\title{
Memory association dynamics on neural network with dynamic synapses
}

Yuichi Katori

From The Twenty Third Annual Computational Neuroscience Meeting: CNS*2014

Québec City, Canada. 26-31 July 2014

Recent physiological studies revealed that the strength of the synaptic connections changes in a short period of time with short-term plasticity (STP) mechanism; these synapse is called dynamic synapse [1]. The synaptic strength decreases (depression synapse) or increases (facilitation synapse) with occurrence of the presynaptic spikes. The STP is suggested to contribute flexible information representation in the prefrontal cortex [2]. Dynamical properties of neural networks with STP have been intensively investigated [3]. In the associative memory network with STP, the STP contribute to generate variety of dynamical states including transitive dynamics among stored memory patterns.

In the present study, we further explore the dynamical properties of the associative memory network with stochastic binary neuron model. Changes in the synaptic transmission efficacy can be modeled with variables that represent the releasable neurotransmitter and the utiliza-

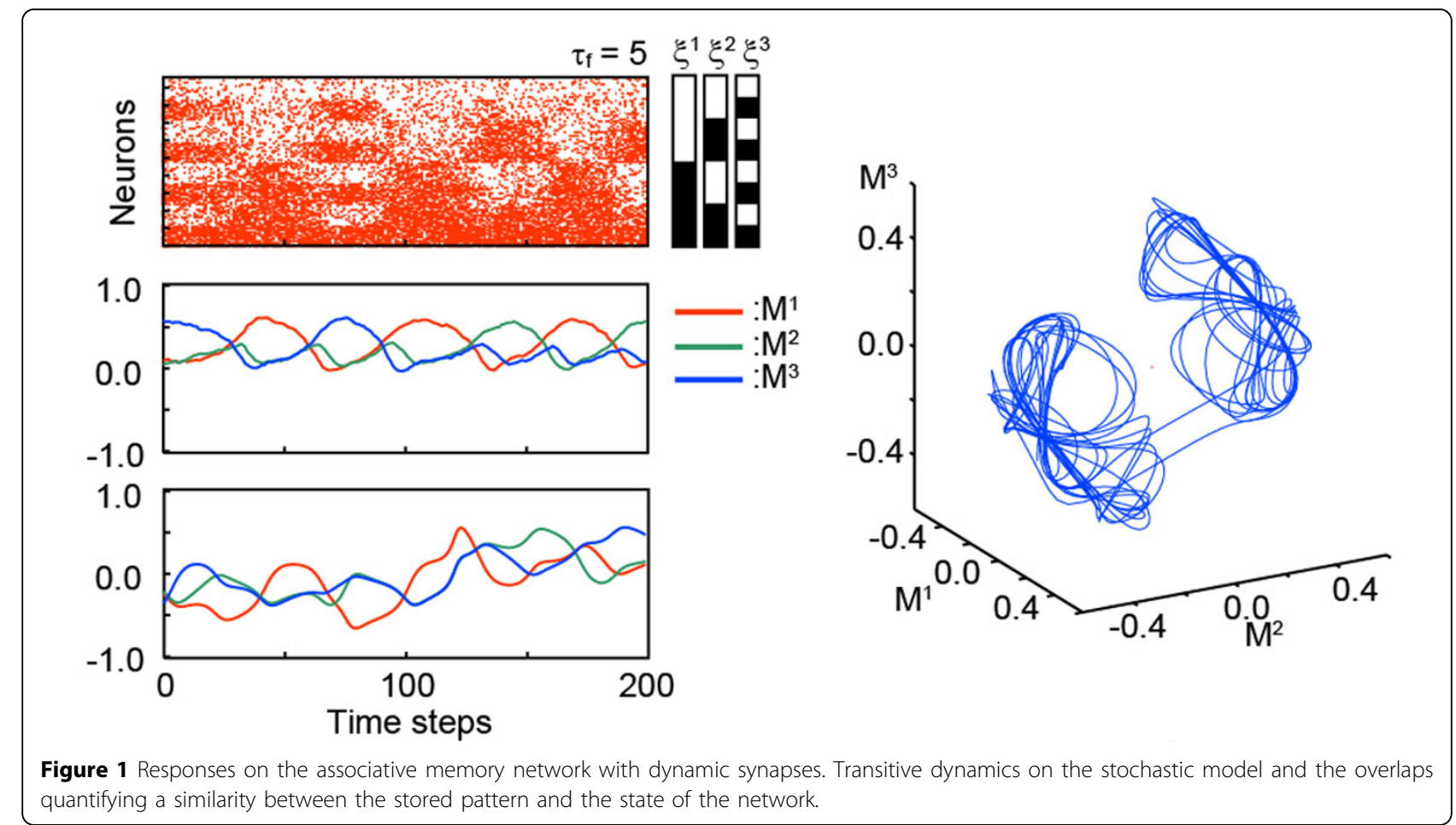

Correspondence: katori@sat.t.u-tokyo.ac.jp

Institute of Industrial Science, The University of Tokyo, Japan

(c) 2014 Katori; licensee BioMed Central Ltd. This is an Open Access article distributed under the terms of the Creative Commons 
tion parameter reflecting the calcium concentration on presynaptic terminal. We drive the dynamical mean field model that allows to analyze detailed bifurcation structure of network dynamics of the stochastic model. We evaluate the memory retrieve performance with applying external input.

\section{Conclusion}

In the associative memory network with dynamic synapses, the network shows variety of dynamical state including memory retrieved states and transitive states among the memory patterns.

\section{Acknowledgements}

This research is supported by JSPS Grant-in-Aid for Young Scientist (B) Grant Number 25730175 and Aihara Innovative Mathematical Modelling Project, the Japan Society for the Promotion of Science (JSPS) through FIRST Program.

Published: 21 July 2014

\section{References}

1. Tsodyks M, Pawelzik K, Markram H: Neural networks with dynamic synapses. Neural Computation 1998, 10(4):821-835.

2. Katori Y, Otsubo Y, Okada M, Aihara K: Stability analysis of associative memory network composed of stochastic neurons and dynamic synapses. Frontiers in Computational Neuroscience 2013, 7:6.

3. Katori Y, Sakamoto K, Saito N, Tanji J, Mushiake H, Aihara K: Representational Switching by Dynamical Reorganization of Attractor Structure in a Network Model of the Prefrontal Cortex. PLoS Computational Biology 2011, 7(11):e1002266.

doi:10.1186/1471-2202-15-S1-P128

Cite this article as: Katori: Memory association dynamics on neural network with dynamic synapses. BMC Neuroscience 2014 15(Suppl 1): P128.

\section{Submit your next manuscript to BioMed Central} and take full advantage of:

- Convenient online submission

- Thorough peer review

- No space constraints or color figure charges

- Immediate publication on acceptance

- Inclusion in PubMed, CAS, Scopus and Google Scholar

- Research which is freely available for redistribution

Submit your manuscript at www.biomedcentral.com/submit
C Biomed Central 